\title{
Game Motorik : Kenali Hewan Dengan Langkahmu
}

\author{
Muhammad Khifli Yusuf Noor ${ }^{1}$, Endah Sudarmilah ${ }^{2}$ \\ Program Studi Informatika, Universitas Muhammadiyah Surakarta \\ Email: ${ }^{1}$ kifliyusuf97@gmail.com , ${ }^{2}$ endah.sudarmilah@ums.ac.id
}

\begin{abstract}
Abstrak: Game merupakan suatu sarana bermain bagi anak-anak, tidak terkecuali anak usia sekolah dasar. Game ada banyak jenisnya salah satunya adalah game edukasi motorik, game motorik adalah game yang dirancang untuk merangsang sistem motorik pada anak agar lebih berkembang lagi. Saat ini game edukasi kurang menekankan sisi motorik pada anak sehingga anak akan meningkat pada kemampuan berpikirnya namun tidak pada sisi motoriknya, tujuan dibuatnya game ini adalah merancang bangun aplikasi motorik anak untuk melatih pengenalan hewan pada anak, Game ini dibuat menggunakan platform 2 dimensi dan menggunakan aplikasi pendukung sebagai penghubung antara game dengan controllernya yang berupa dance pad, rancang bangun game ini menggunakan metode SDLC waterfall. Game motorik ini diuji menggunakan metode blackbox dan metode usability dengan jumlah 30 responden. Pengujian game ini mendapatkan hasil 82,7 dan menujukan hasil sangat baik.
\end{abstract}

Kata Kunci: Game, edukasi, motorik, dancepad

\begin{abstract}
Games are a means of playing for children, no exception elementary school children. There are many types of games, one of which is a motoric education game, motoric games are games that are designed to stimulate the motoric system in children to develop even more. Currently the educational game lacks emphasis on the motoric side of the child so that the child will increase his thinking ability but not on the motoric side. the purpose of making this game is to design and build children's motoric applications to train animal recognition in children, this game is made using a 2-dimensional platform and uses supporting applications as a link between the game and the controller in the form of a dance pad, this game uses the SDLC waterfall method. This motoric game was tested using the blackbox method and the usability method with a total of 30 respondents. Testing this game got 82.7 results and aimed very well.
\end{abstract}

Keywords: Game, education, motoric, dance pad

\section{PENDAHULUAN}

Game edukasi merupakan salah satu media alternatif untuk pembelajaran kepada anakanak karena game banyak disukai oleh anak-anak dan juga merupakan sebuah media pembelajaran yang efektif [1]. Penelitian kali ini adalah merancang bangun game edukasi menyusun nama hewan yang tidak hanya mendidik namun juga merangsang perkembangan motorik anak.

Media pembelajaran untuk anak usia dini seharusnya dapat menimbulkan motivasi dan ketertarikan anak agar anak belajar seperti bermain dan tujuan pembelajaran dapat tercapai secara optimal [2]. Game edukasi dirancang untuk merubah pola belajar anak-anak yang biasanya dengan cara melihat guru menulis dipapan tulis dan mendengarkan guru berbicara, masalah yang dihadapi seperti lemahnya kemauan belajar anak karena masih berbasis text book, diperlukan sebuah aplikasi yang memacu sensor motorik anak menggunakan aplikasi game edukasi berbasis mobile [3]. Salah satu kelebihan utama game edukasi adalah pada visualisasi dari permasalahan nyata. Berdasarkan pola yang dimiliki oleh game tersebut, pemain dituntut untuk belajar sehingga dapat menyelesaikan permasalahan yang ada [4]. Namun pada beberapa penelitian di atas terdapat suatu kelemahan yaitu kurangnya sisi motorik pada game yang dibuat, pada penelitian terdahulu hanya meningkatkan perkembangan motorik halus anak, melatih kontrol otot kecil, koordinasi mata, dan jari [5]. 
Muhammad Khifli, Y.N, dkk//Journal of Technology and Informatics (JoTI) Vol.1 No.2, April 2020, 73-79

Pembuatan game edukasi harus menitik beratkan kepada pengembangan game atau permainannya yang interaktif karena game atau permainan interaktif ini yang menjadi wadah utama dalam penyampaian pembelajaran bagi anak di usia dini [6], mayoritas anak-anak (63\%) dapat menggunakan game edukasi dengan baik karena mereka terbiasa dengannya [7]. Oleh karena itu dapat di simpulkan jika rumusan masalah dalam pembuatan game ini yaitu bagaimana merancang bangun aplikasi game motorik yang baik dan benar untuk anak, karena pada kebanyakan game edukasi sekarang ini kurang menekankan sisi motoriknya sehingga anak akan meningkat pada kemampuan berpikirnya namun tidak pada sisi motoriknya.

Berdasarkan usia anak sekolah dasar yang masih tergolong usia dini merupakan kesempatan emas bagi si anak untuk belajar, sehingga disebut dengan usia emas (golden age), mengingat usia dini merupakan usia emas maka pada masa itu perkembangan anak harus dioptimalkan [8]. Pada masa ini anak harus diberi pembelajaran tentang hewan yang benar agar di masa depan anak dapat mengetahui tentang berbagai macam hewan, jadi tujuan dari penelitian ini yaitu merancang bangun aplikasi motorik anak untuk melatih pengenalan hewan, tempat hidup hewan dan mengetahui perbedaan jenis hewan pada anak.

\section{METODE}

Adapun metode yang digunakan yaitu menggunakan metode SDLC (System Development Life Cycle) dengan model Waterfall. Dimana berisi rangkaian aktivitas proses yang teratur dan disajikan dalam proses yang terpisah [9], rangkaian aktivitas tersebut adalah analisa kebutuhan, desain, coding, dan pengujian seperti yang ditampilkan pada Gambar 1 berikut.

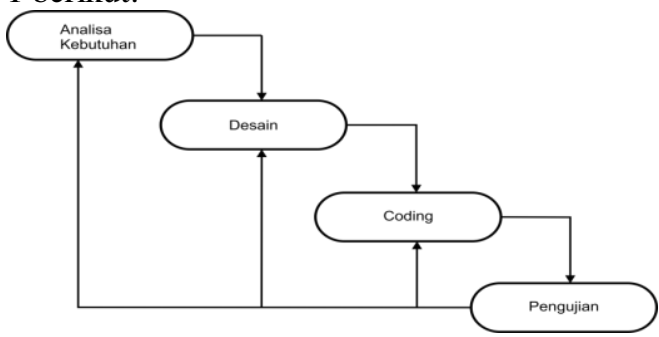

Gambar 1. Model SDLC Waterfall [10]
Storyline merupakan deskripsi alur cerita game yang dibentuk menjadi sebuah teks/narasi. Storyline dari game edukasi mengenal hewan ini yaitu game ini memiliki 6 button yaitu arah atas, bawah, kanan, kiri, serta tombol OK dan kembali, pada setiap level atau soal terdapat life dan timer. jumlah poin akan di dapat tergantung seberapa cepat dalam menjawab soal, jika tedapat kesalahan dalam menjawab soal akan muncul peringatan dan life akan berkurang, jika life habis atau menjadi 0 maka akan game over dan jika timer habis sebelum soal selesai maka soal akan merestart. Game ini memiliki 3 level, pada level 1 berisi tentang pengenalan tubuh hewan, level 2 berisi tentang tempat hidup hewan dan level 3 berisi tentang jenis-jenis hewan. Setiap akhir soal akan terdapat penjelasan mengenai hewan yang ada di soal tersebut.

\section{Hardware dan software}

Kebutuhan hardware dan software bisa dilihat pada Tabel 1.

Tabel 1 Hardware dan Software

\begin{tabular}{|l|l|}
\hline \multicolumn{1}{|c|}{ Hardware } & \multicolumn{1}{c|}{ Software } \\
\hline Laptop Asus S200E & Sistem Operasi \\
Intel Core i3, RAM & Windows 10 \\
\cline { 2 - 2 } $\begin{array}{l}\text { 4GB, Harddisk } \\
\text { 500GB }\end{array}$ & Aplikasi Construct 2 \\
\hline Koneksi Internet & Corel Draw 2018 \\
\hline \multirow{2}{*}{ Step pad } & Aplikasi JoyToKey \\
\cline { 2 - 2 } & NW.js for Construct 2 \\
\hline
\end{tabular}

\section{Desain}

\section{Usecase}

Berikut merupakan usecase dari user yang terdapat pada Gambar 2, dan usecase dari admin yang terdapat pada Gambar 3 .

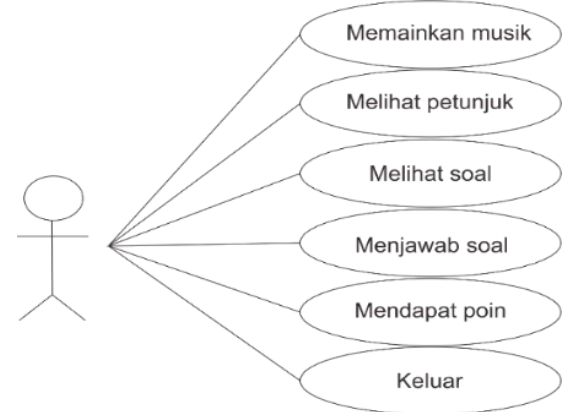

Gambar 2. Usecase user

\section{Analisa Kebutuhan}


Muhammad Khifli, Y.N, dkk//Journal of Technology and Informatics (JoTI) Vol.1 No.2, April 2020, 73-79

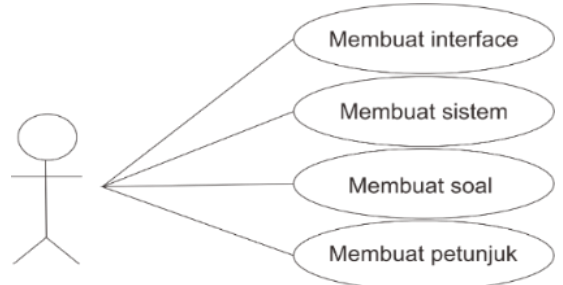

Gambar 3. Usecase admin

\section{Activity diagram}

Activity diagram game mengenal hewan bisa dilihat pada Gambar 4.

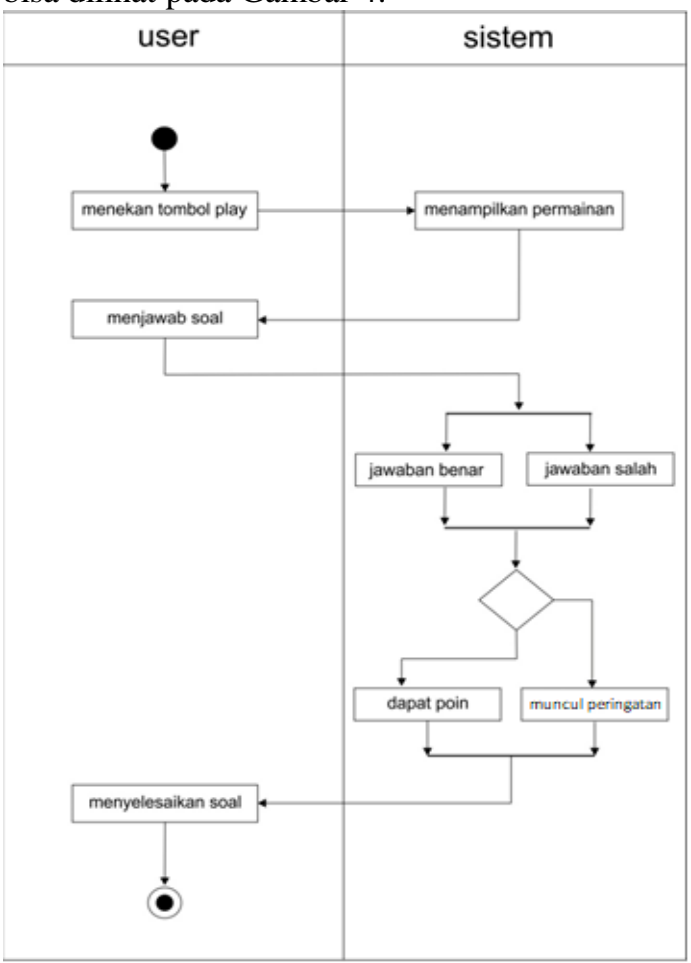

Gambar 4. Activity diagram

\section{Pengujian}

Pengujian yang digunakan dalam penelitian ini menggunakan metode blackbox dan usability. Sedangkan, pengujian usabilitynya, menggunakan kuisioner.

\section{HASIL DAN PEMBAHASAN Hasil Tampilan Game Menu Utama}

Menu yang pertama kali terlihat saat membuka game pengenalan hewan seperti yang terdapat pada Gambar 5.

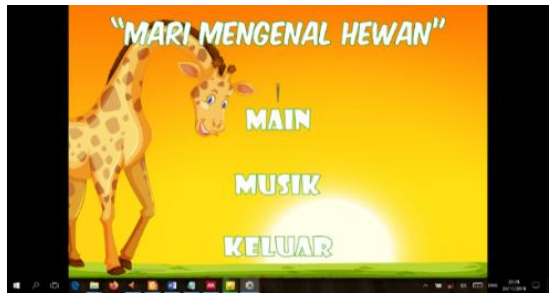

Gambar 5. Tampilan menu utama

\section{Menu Petunjuk}

Gambar 6.

Menu petunjuk level 1 bisa dilihat pada

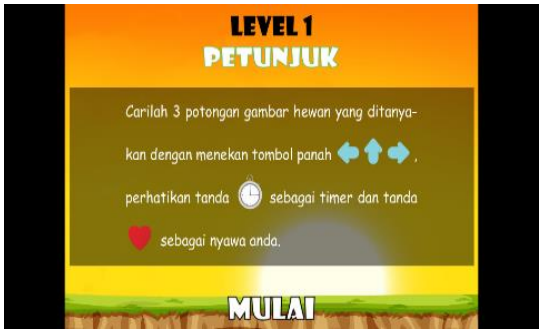

Gambar 6. Tampilan petunjuk level 1 Gambar 7.

Menu petunjuk level 2 bisa dilihat pada

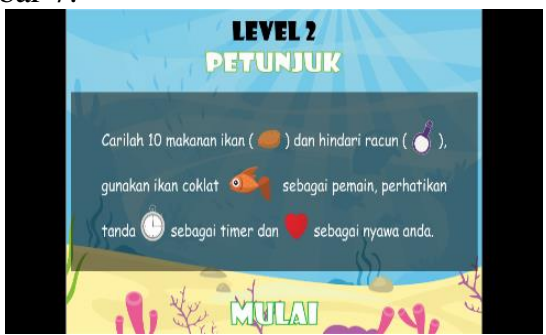

Gambar 7. Tampilan petunjuk level 2

\section{Tampilan Permainan}

Berikut merupakan tampilan game level 1 yang bertema tentang pengenalan bagian utama tubuh hewan serta kegunaanya yang bisa dilihat pada Gambar 8.

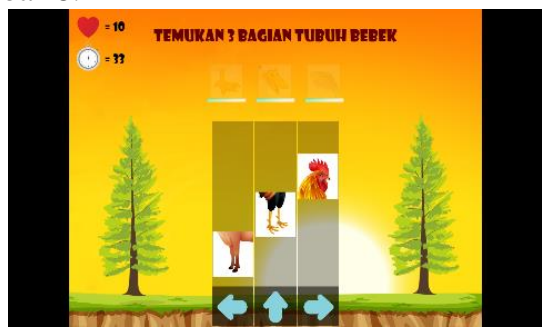

Gambar 8. Tampilan game level 1

Berikut merupakan tampilan game level 2 yang bertema tentang tempat hidup hewan yang bisa dilihat pada Gambar 9 
Muhammad Khifli, Y.N, dkk//Journal of Technology and Informatics (JoTI) Vol.1 No.2, April 2020, 73-79

Tabel 2 Pengujian BlackBox

\begin{tabular}{|c|c|c|c|c|}
\hline No & Item & Input & Output & Hasil \\
\hline \multirow{3}{*}{1} & \multirow{3}{*}{ Menu Utama } & Klik tombol main & Masuk ke menu Petunjuk & Diterima \\
\hline & & Klik tombol musik & Masuk ke menu musik & Diterima \\
\hline & & Klik tombol keluar & Keluar dari game & Diterima \\
\hline \multirow{2}{*}{2} & \multirow{2}{*}{ Menu musik } & Klik hidupkan & Musik Hidup & Diterima \\
\hline & & Klik matikan & Musik Mati & Diterima \\
\hline \multirow[t]{2}{*}{3} & \multirow[t]{2}{*}{$\begin{array}{l}\text { Memainkan } \\
\text { Game }\end{array}$} & $\begin{array}{l}\text { Memasukkan Gambar } \\
\text { dengan benar }\end{array}$ & Gambar akan muncul & Diterima \\
\hline & & Memasukkan gambar salah & Muncul peringatan & Diterima \\
\hline \multirow{2}{*}{4} & \multirow{2}{*}{$\begin{array}{l}\text { Menu game } \\
\text { over }\end{array}$} & Klik Main Lagi & $\begin{array}{l}\text { Kembali memainkan soal yang } \\
\text { sama }\end{array}$ & Diterima \\
\hline & & Klik Menu Utama & $\begin{array}{l}\text { Keluar dari permainan dan masuk } \\
\text { ke menu utama }\end{array}$ & Diterima \\
\hline 5 & Peringatan & Salah memasukkan gambar & Muncul peringatan & Diterima \\
\hline 6 & $\begin{array}{l}\text { Menu } \\
\text { Petunjuk }\end{array}$ & Klik Mulai & Masuk ke permainan & Diterima \\
\hline \multirow[b]{2}{*}{7} & \multirow{2}{*}{$\begin{array}{c}\text { Menu } \\
\text { Penjelasan } \\
\text { Hewan }\end{array}$} & Klik soal/level berikutnya & Pergi ke soal selanjutnya & Diterima \\
\hline & & Klik main lagi & $\begin{array}{l}\text { Kembali memainkan soal yang } \\
\text { sama }\end{array}$ & Diterima \\
\hline
\end{tabular}

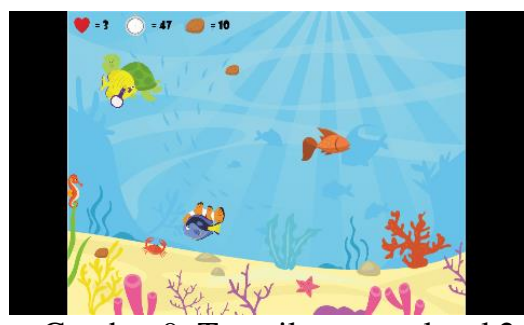

Gambar 9. Tampilan game level 2

\section{Hasil Permainan}

Berikut merupakan hasil dari game yang dimainkan pada level 1 yang bisa dilihat pada Gambar 10.

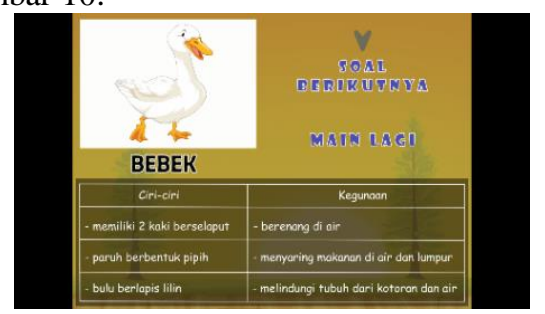

Gambar 10. Hasil game level 1

Berikut merupakan hasil dari game yang dimainkan pada level 2 yang bisa dilihat pada Gambar 11.

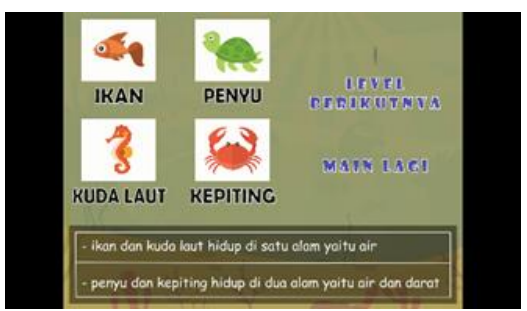

Gambar 11. Hasil game level 2

\section{Menu Game Over dan Menang}

Berikut merupakan tampilan game over yang bisa dilihat pada Gambar 12.

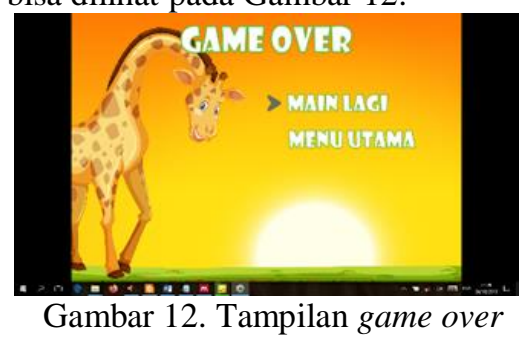

Berikut merupakan tampilan selamat/ menang karena telah menyelesaikan suatu level yang bisa dilihat pada Gambar 13. 
Muhammad Khifli, Y.N, dkk//Journal of Technology and Informatics (JoTI) Vol.1 No.2, April 2020, 73-79

Tabel 3 Pengujian Usability SUS

\begin{tabular}{|c|c|c|c|c|c|c|c|c|c|c|c|c|}
\hline \multirow[b]{2}{*}{$\begin{array}{c}\text { No } \\
\text { Responden } \\
\end{array}$} & \multicolumn{11}{|c|}{ Kalkulasi Pertanyaan } & \multirow{2}{*}{$\begin{array}{c}\text { Skor } \\
\text { SUS } \\
\text { (jumlah } \\
\text { x 2,5) } \\
\end{array}$} \\
\hline & P1 & $\mathbf{P 2}$ & P3 & P4 & P5 & P6 & P7 & P8 & P9 & P10 & Jumlah & \\
\hline 1 & 3 & 3 & 3 & 3 & 4 & 3 & 4 & 1 & 1 & 4 & 29 & 72,5 \\
\hline 2 & 4 & 4 & 3 & 3 & 4 & 4 & 3 & 3 & 4 & 4 & 36 & 90 \\
\hline 3 & 3 & 2 & 4 & 1 & 4 & 4 & 4 & 2 & 4 & 1 & 29 & 72,5 \\
\hline 4 & 4 & 4 & 3 & 3 & 4 & 4 & 3 & 3 & 4 & 4 & 36 & 90 \\
\hline 5 & 4 & 3 & 4 & 1 & 4 & 4 & 4 & 2 & 4 & 1 & 31 & 77,5 \\
\hline 6 & 4 & 4 & 3 & 3 & 4 & 4 & 3 & 3 & 4 & 4 & 36 & 90 \\
\hline 7 & 3 & 2 & 4 & 3 & 4 & 4 & 3 & 3 & 4 & 4 & 34 & 85 \\
\hline 8 & 4 & 2 & 2 & 1 & 4 & 0 & 4 & 0 & 4 & 0 & 21 & 52,5 \\
\hline 9 & 3 & 3 & 4 & 3 & 4 & 3 & 4 & 2 & 4 & 4 & 34 & 85 \\
\hline 10 & 4 & 4 & 3 & 3 & 4 & 4 & 3 & 3 & 4 & 4 & 36 & 90 \\
\hline 11 & 0 & 3 & 2 & 1 & 4 & 4 & 3 & 0 & 2 & 0 & 19 & 47,5 \\
\hline 12 & 4 & 4 & 1 & 3 & 4 & 4 & 3 & 3 & 4 & 4 & 34 & 85 \\
\hline 13 & 4 & 2 & 2 & 0 & 4 & 4 & 4 & 0 & 4 & 0 & 24 & 60 \\
\hline 14 & 4 & 4 & 3 & 3 & 4 & 4 & 3 & 3 & 4 & 4 & 36 & 90 \\
\hline 15 & 3 & 3 & 4 & 1 & 4 & 1 & 4 & 2 & 4 & 1 & 27 & 67,5 \\
\hline 16 & 4 & 4 & 3 & 3 & 4 & 4 & 3 & 3 & 4 & 4 & 36 & 90 \\
\hline 17 & 4 & 3 & 4 & 3 & 4 & 3 & 4 & 3 & 4 & 3 & 35 & 87,5 \\
\hline 18 & 4 & 4 & 3 & 3 & 4 & 4 & 3 & 3 & 4 & 4 & 36 & 90 \\
\hline 19 & 4 & 4 & 3 & 3 & 4 & 4 & 3 & 3 & 4 & 4 & 36 & 90 \\
\hline 20 & 4 & 3 & 3 & 3 & 4 & 4 & 3 & 3 & 4 & 4 & 35 & 87,5 \\
\hline 21 & 4 & 4 & 3 & 3 & 4 & 4 & 3 & 3 & 4 & 4 & 36 & 90 \\
\hline 22 & 4 & 4 & 3 & 3 & 4 & 4 & 3 & 3 & 4 & 4 & 36 & 90 \\
\hline 23 & 4 & 4 & 2 & 3 & 4 & 4 & 3 & 3 & 4 & 4 & 35 & 87,5 \\
\hline 24 & 4 & 4 & 3 & 3 & 4 & 4 & 3 & 3 & 4 & 4 & 36 & 90 \\
\hline 25 & 4 & 3 & 4 & 1 & 4 & 3 & 4 & 3 & 4 & 3 & 33 & 82,5 \\
\hline 26 & 4 & 4 & 3 & 3 & 4 & 4 & 3 & 3 & 4 & 4 & 36 & 90 \\
\hline 27 & 4 & 3 & 3 & 3 & 4 & 4 & 3 & 3 & 4 & 4 & 35 & 87,5 \\
\hline 28 & 4 & 4 & 3 & 3 & 4 & 4 & 3 & 3 & 4 & 4 & 36 & 90 \\
\hline 29 & 4 & 3 & 4 & 3 & 4 & 3 & 4 & 3 & 4 & 3 & 35 & 87,5 \\
\hline 30 & 4 & 3 & 3 & 3 & 4 & 3 & 4 & 3 & 4 & 3 & 34 & 85 \\
\hline & & & & JuI & nlah & KOr s & & & & & & 2480 \\
\hline
\end{tabular}




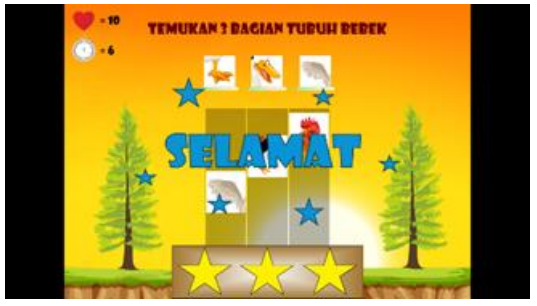

Gambar 13. Tampilan selamat/menang

\section{Pengujian Blackbox}

Pengujian blackbox adalah pengujian berdasarkan spesifikasi persyaratan dan tidak perlu memeriksa kode, jadi persyaratan yang tidak dapat diprediksi dapat dengan mudah diidentifikasi dan dapat diatasi [11]. Berikut merupakan pengujian blackbox game mengenal hewan yang terdapat pada Tabel 2 .

\section{Pengujian Usability}

Uji usability mengacu kepada bagaimana pengguna bisa mempelajari dan menggunakan produk untuk memperoleh tujuannya dan seberapa puaskah mereka terhadap penggunannya. Saat memainkan game ini rangsangan motorik pada anak langsung terlatih dikarenakan alat yang digunakan untuk memainkan gamenya adalah dancepad, uji usability game mengenal hewan ini menggunakan metode SUS (System Usability Scale) dengan 30 responden, berikut merupakan uji usability SUS

SUS yaitu 2480, hasil perhitungan tersebut dapat dibuat menjadi grafik seperti pada Gambar 15 .

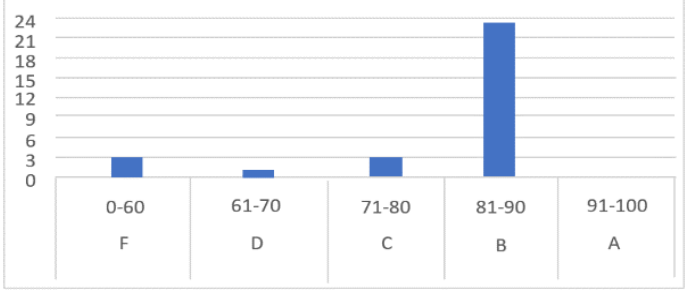

Gambar 15. Grafik hasil perhitungan SUS

Sumbu tegak pada Gambar 20 merupakan jumlah responden sedangkan angka yang berada dibawah grafik merupakan nilai yang diperoleh dari setiap responden. Kemudian mencari nilai rata-rata dari jumlah skor SUS, yang dapat dilihat pada Persamaan 1. yang terdapat pada Tabel 3. Dimana dari Tabel 3 tersebut P1 adalah Aplikasi sangat disukai dan akan menggunakannya berkali-kali. P2 menunjukkan aplikasi yang terlalu rumit digunakan. P3 aplikasi mudah digunakan. P4 membutuhkan bantuan orang laian dalam menggunakan aplikasi. P5 adalah bagian-bagian dapat digunakan dengan baik. P6 aplikasi yang membingungkan. P7 orang lain akan menggunakan aplikasi ini dengan mudah dan cepat. P8 Aplikasi ini tidak praktik atau sulit digunakan. P9 boleh menggunakan aplikasi ini. P10 perlu belajar banyak untuk menggunakan aplikasi ini. Nilai dari 1 menunjukkan sangat tidak setuju, Nilai 2 tidak setuju. Nilai 3 menunjukkan Ragu. Nilai 4 menunjukkan Setuju dan Nilai 5 menunjukkan tidak setuju.

Dibawah ini merupakan grafik tolak ukur peringkat SUS yang digunakan sebagai penilaian bagus atau tidaknya suatu sistem yang bisa dilihat pada Gambar 14.

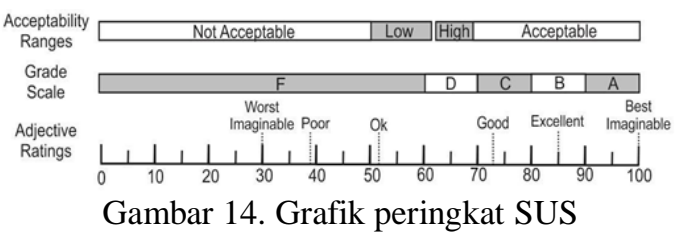

Hasil perhitungan uji usability SUS pada Tabel 3, menghasilkan jumlah skor

Nilai rata - rata $=\sum_{i=1}^{n} \frac{x_{i}}{N}$

dimana:

$x_{i}:$ Jumlah score SUS

$N$ : Jumlah responden

Rata Jumlah Score SUS $=\frac{2480}{30}=82,7$

Nilai rata - rata jumlah skor SUS mendapatkan hasil 82,7 yang dapat dilihat pada Persamaan 2, kemudian dilihat seberapa baik sistem aplikasi dengan tolak ukur peringkat skor SUS. Game edukasi mengenal hewan menujukan hasil pada peringkat B yang dapat diartikan sangat baik (excellent) dan dapat diterima (acceptable).

\section{KESIMPULAN}

Berdasarkan hasil penelitian sebelumnya, tidak diragukan lagi bahwa game edukasi dapat menunjang proses pendidikan. 
Muhammad Khifli, Y.N, dkk//Journal of Technology and Informatics (JoTI) Vol.1 No.2, April 2020, 73-79

Game edukasi unggul dalam beberapa aspek jika dibandingkan dengan metode pembelajaran konvensional [12]. Dengan adanya game edukasi anak dapat memperoleh pengetahuan baru di dalam dunia teknologi serta pengetahuan mengenai gambar gambar tertentu seperti hewan [13].

Game edukasi mengenal hewan ini dibuat dengan menyesuaikan kurikulum pembelajaran anak usia sekolah dasar, jadi anak akan lebih terbantu dalam proses belajar mengajarnya karena game edukasi ini berisi sama dengan materi yang diajarkan di sekolah dan di buku paket.

Hasil pengujian game edukasi ini juga cukup baik mengingat game ini diujikan kepada anak SD. Pada uji blackbox game edukasi ini sudah berfungsi dengan baik, sedangkan uji usability game ini pun memperoleh nilai rata-rata sebesar 82,7 yang berarti game ini dapat diterima dengan baik.

\section{DAFTAR PUSTAKA}

[1] Syukur, A., \& Fitra, A. (2017). Game Interaksi Pengenalan Huruf dan Perangkaian Kata. Seminar Nasional Teknologi Dan Multimedia 2017, (2017), 7-12. Retrieved from http://ojs.amikom.ac.id/index.php/semnast eknomedia/article/viewFile/1731/1459

[2] Herman, Saleh, S., \& Islami, N. M. (2017). Penerapan Media Aplikasi Education Games Berbasis Budaya Lokal Untuk Meningkatkan Kemampuan Membaca Permulaan. 481-486.

[3] Efendi, Y. (2018). Rancangan Aplikasi Game Edukasi Berbasis Mobile Menggunakan App Inventor. Jurnal IndtraTech, 2(1).

[4] Vitianingsih, A. V. (2016). Game Edukasi Berbasis Android Sebagai Media Pembelajaran Untuk Anak Usia Dini. 1(1), 46-58.

[5] Kusuma, G. \& E. S. (2016). Pengembangan Permainan Labirin untuk Membantu Perkembangan Motorik Anak. Jurnal Fakultas Teknik Universitas Khairun, 03(2354 - 8924), 46 - 89 |.

[6] Rahman, R. A., \& Tresnawati, D. (2016). Pengembangan Game Edukasi Pengenalan Nama Hewan dan Habitatnya Dalam 3 Bahasa Sebagai Media Pembelajaran Berbasis Multimedia. Jurnal Algoritma
Sekolah Tinggi Teknologi Garut, 13(1), 184-190. Retrieved from http://www.jurnal.sttgarut.ac.id/index.php/ algoritma/article/view/323

[7] Siregar, S., Wau, H., \& Hartini, S. (2018). The Relationship Between Educational Games and the Development of Motor, Language, and Social Skills in Children Ages 3-4 Years. KnE Life Sciences, 4(4), 43. https://doi.org/10.18502/kls.v4i4.2262

[8] Dwiyogo, N. K. M. W. D., \& Heynoek, F. P. (2017). Pengembangan Permainan Aku Dan Hewan Menggunakan Multimedia Interaktif Untuk Guru Anak Usia Dini. Kajian Teori, Praktik Pendidikan Dan Pembelajaran, no.1(No.1), 153-165.

[9] Sudarmilah, E., \& Wibowo, P. A. (2016). Aplikasi Augmented Reality Game Edukasi Untuk Pengenalan Organ Tubuh Manusia. Khazanah Informatika: Jurnal Ilmu Komputer Dan Informatika, 2(1), 20. https://doi.org/10.23917/khif.v2i1.1945

[10] Shalahuddin, M., \& Sukamto, R. A. (2018). Rekayasa Perangkat Lunak Terstruktur dan Berorientasi Objek Edisi Revisi. Informatika Bandung.

[11] Nidhra, S., \& Dondeti, J. (2012). Black Box and White Box Testing Techniques. International Journal of Embedded Systems and Applications (IJESA), 2(2), 29-50.

[12] Nuqisari, R., \& Sudarmilah, E. (2019). Pembuatan Game Edukasi Tata Surya dengan Construct 2 Berbasis Android. 19(02), 90-96.

[13] Sakkinah, I. S., Mushawwir, M., Wardani, N. E., \& Prasetya, D. D. (2016). Adventure Alphabet Game: Game Pengenalan Huruf. 8, 164-167. 